\title{
Dyslipidemia and reference values for fasting plasma lipid concentrations in Danish/North-European White children and adolescents
}

Tenna Ruest Haarmark Nielsen 1,2*, Ulrik Lausten-Thomsen 1,3, Cilius Esmann Fonvig ${ }^{1,2,4}$, Christine Bøjsøe $e^{1,2}$, Lise Pedersen ${ }^{5}$, Palle Skov Bratholm ${ }^{5}$, Torben Hansen ${ }^{2}$, Oluf Pedersen ${ }^{2}$ and Jens-Christian Holm ${ }^{1,2,3}$

\begin{abstract}
Background: Dyslipidemia is reported in 27 - 43\% of children and adolescents with overweight/obesity and tracks into adulthood, increasing the risk of cardiovascular morbidity. Cut-off values for fasting plasma lipid concentrations are typically set at fixed levels throughout childhood. The objective of this cross-sectional study was to generate fasting plasma lipid references for a Danish/North-European White population-based cohort of children and adolescents, and investigate the prevalence of dyslipidemia in this cohort as well as in a cohort with overweight/obesity.

Methods: A population-based cohort of 2141 (1275 girls) children and adolescents aged 6 - 19 (median 11.5) years was recruited from 11 municipalities in Denmark. Additionally, a cohort of children and adolescents of 1421 (774 girls) with overweight/obesity aged 6 - 19 years (median 11.8) was recruited for the study. Height, weight, and fasting plasma lipid concentrations were measured on all participants. Smoothed reference curves and percentiles were generated using the Generalized Additive Models for Location Scale and Shape package in the statistical software R.

Results: In the population-based cohort, plasma concentrations of total cholesterol (TC) $(P<0.05)$, low-density lipoprotein cholesterol (LDL) $(P<0.005)$, and high-density lipoprotein cholesterol $(\mathrm{HDL})(P<0.005)$ were higher in the youngest compared to the oldest tertile. Fasting plasma levels of triglycerides (TG) $(P<0.005)$ increased with age in both sexes. In boys, non-HDL was lower in the oldest compared to the youngest tertile $(P<0.0005)$.

Concentrations of TC, LDL, non-HDL, and TG were higher $(P<0.05)$, and HDL lower $(P<0.05)$ in the cohort with overweight/ obesity in both sexes and for all ages except for TC in the youngest girls. The overall prevalence of dyslipidemia was $6.4 \%$ in the population-based cohort and $28.0 \%$ in the cohort with overweight/obesity. The odds ratio for exhibiting dyslipidemia in the cohort with overweight/obesity compared with the population-based cohort was 6.2 (95\% Cl: $4.9-8.1, P<2^{*} 10^{-16}$ ).

Conclusion: Fasting plasma lipid concentrations change during childhood and adolescence and differ with sex and age. Children and adolescents with obesity have increased concentrations of circulating lipids and exhibit an increased prevalence of dyslipidemia.
\end{abstract}

Trial registration: The study is part of The Danish Childhood Obesity Biobank; ClinicalTrials.gov ID-no.: NCT00928473 retrospectively registered on June 25th 2009.

Keywords: Adolescent, Child, Dyslipidemias, Lipids, Obesity, Reference values

\footnotetext{
* Correspondence: ter@regionsjaelland.dk

${ }^{1}$ The Children's Obesity Clinic, Department of Pediatrics, Copenhagen University

Hospital Holbæk, Smedelundsgade 60, DK 4300 Holbæk, Denmark

${ }^{2}$ Novo Nordisk Foundation Center for Basic Metabolic Research, Section of

Metabolic Genetics, University of Copenhagen, DK 2100 Copenhagen, Denmark

Full list of author information is available at the end of the article
} 


\section{Background}

Cardiovascular disease (CVD) is still the major cause of mortality in the world [1]. Elevated concentrations of circulating total cholesterol (TC), low-density lipoprotein (LDL), non-high-density lipoprotein (non-HDL), and triglycerides (TG), and reduced HDL, in addition to other well known risk factors such as obesity, smoking, diabetes, and hypertension, are associated with the development of atherosclerotic disease [2-5]. Elevated lipid concentrations during childhood track into adulthood and increase the risk of CVD, and thus morbidity and mortality [6-9]. Similarly, obesity tracks into adulthood $[10,11]$, and is positively associated with dyslipidemia $[12,13]$. Up to $27 \%$ of Danish [13] and $43 \%$ of American children and adolescents [14] with overweight/obesity exhibit dyslipidemia, and early treatment and prevention is required [2].

The American Academy of Pediatrics currently recommends that children with obesity or familial aggregation of hyperlipidemia should have their lipid concentrations monitored regularly [15]. Consistent with the increased prevalence of obesity in childhood [16-19], the proportion of children who require screening for dyslipidemia, is increasing.

A prerequisite for the correct identification of dyslipidemia in children and adolescents is the definition of normal ranges of circulating lipid concentrations. Lipid concentrations differ with age, sex, and ethnicity [15], and accordingly age and sex specific reference values from each region/ethnicity is warranted. Current cut-offs for dyslipidemia in children and adolescents are based on data from the North American National Cholesterol Education Program [15]. Based on these cut-offs, 20\% of American adolescents exhibit dyslipidemia [20]. A recent European study found similar prevalence of childhood dyslipidemia in a German cohort [21].

The present study aims to identify fasting plasma lipid concentrations from a population-based cohort of Danish/North-European White children and adolescents, and from a normal weight subgroup of this cohort. In addition, the study aims to explore any differences in fasting plasma lipid concentrations between the population-based cohort and children and adolescents with overweight/obesity.

\section{Methods}

\section{Study populations}

From October 2010 until February 2015, a populationbased cohort of children and adolescents from schools across 11 municipalities in Denmark were phenotyped ( $N=2836)$. This population-based cohort was extended with children 6 - 9 years of age recruited from March 2015 until March 2016 via the public dentistry and health care nurses in one of these municipalities $(N=189)$.
Phenotyping was performed by trained medical staff and involved an extensive questionnaire, a clinical examination, including height and weight, and a fasting blood sample. The questionnaire was completed at home before the examination.

Exclusion criteria for this study were 1) no blood samples available $(N=112), 2)$ missing data on lipid concentrations $(N=235), 3)$ more than 30 days between blood sampling and height and weight measurements $(N=10)$, 4) ethnicity other than Danish/North-European White $(N=470)$, 5) known familial hypercholesterolemia $(N=0), 6)$ use of cholesterol-lowering medications $(N=0)$, and 7) age younger than 6 years or older than 19 years $(N=57)$, leaving 2141 participants for further analyses (Fig. 1).

From the population-based cohort, a normal weight subgroup of 1639 (971 girls) children and adolescents was defined by a body mass index (BMI) $\leq$ 90th and $\geq 10$ th percentile for age and sex according to Danish references [22].

From The Children's Obesity Clinic (TCOC), Department of Pediatrics, Copenhagen University Hospital Holbæk, 1759 children and adolescents with a BMI above the 90th percentile [22] were included in the study from 2008 until December 2015 (the TCOC cohort). These participants had fasting blood samples collected within 30 days of the measurements of height and weight. Exclusion criteria for the present study were 1) ethnicity other than Danish/North-European White $(N=248), 2)$ known genetic causes of obesity $(N=16)$, 3) known familial hypercholesterolemia $(N=4)$, 4) use of lipid-lowering medication $(N=0)$, and 5$)$ age younger than 6 years or older than 19 years $(N=70)$. This left 1421 children and adolescents with overweight/obesity for further analyses.

\section{Anthropometrics}

Height was measured by stadiometer to the nearest $1 \mathrm{~mm}$. Weight was measured to the nearest $100 \mathrm{~g}$ on a Tanita BC418 scale (Tanita Corp., Tokyo, Japan) in the population-based cohort, and on a Tanita ${ }^{\oplus}$ Digital Medical Scale, WB-110 MA (Tanita Corp., Tokyo, Japan) in the TCOC cohort. Measurements were performed wearing light indoor clothes and without shoes. BMI was calculated as weight divided by height in meters squared. The LMS method [23], which uses the median $(\mathrm{M})$, the coefficient of variation $(\mathrm{S})$, and a measure of the skewness (L) in a Box-Cox transformation to normalize the data, was used to calculate the BMI standard deviation scores (SDS) according to Danish references [22].

\section{Puberty}

In the population-based cohort, the pubertal developmental stage according to the Tanner classification $[24,25]$ 


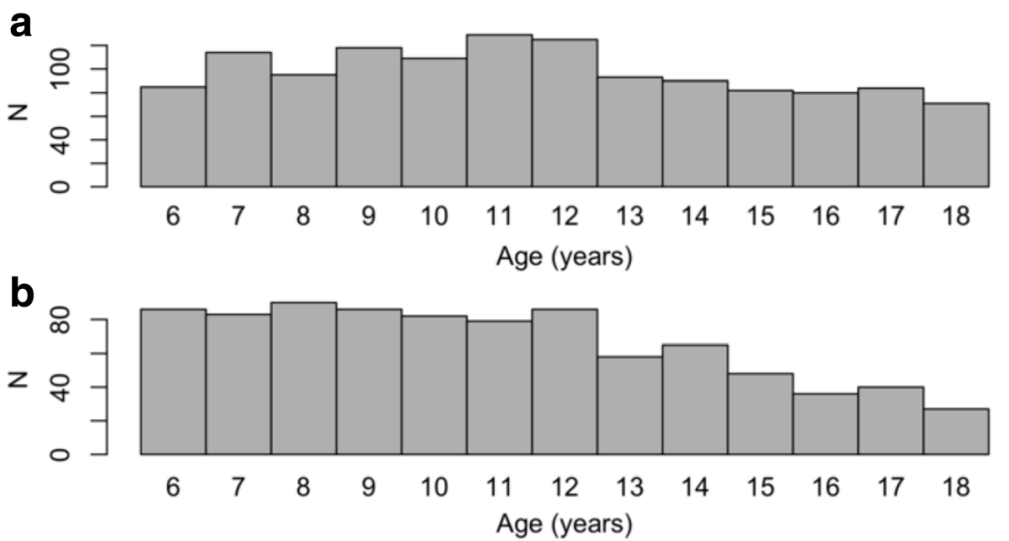

Fig. 1 Age distribution. Number of children and adolescents within each age group in the population-based cohort generating the fasting plasma lipid reference intervals. a Girls. b Boys

was self-evaluated using a descriptive text and color charts for picture pattern recognition. In the TCOC cohort, a pediatrician evaluated the pubertal developmental stage at the first visit to the clinic. Self-evaluated pubertal staging has been shown to adequately describe pre-pubertal versus pubertal status [26]. Therefore, pubertal stage in both the population-based cohort and the TCOC cohort were defined as pre-pubertal (Tanner 1) or pubertal (Tanner 2-5).

\section{Blood samples}

After an overnight fast, venous blood samples were drawn between 7 and $9 \mathrm{AM}$, processed within $1 \mathrm{~h}$, and analyzed within $6-8 \mathrm{~h}$ after sampling at the Department of Clinical Biochemistry, Copenhagen University Hospital Holbæk. Analyses were, until May 15th 2013, performed on a Cobas 6000 (Roche Diagnostics, Mannheim, Germany) ( $\mathrm{N}_{\text {population-based }}=699, \mathrm{~N}_{\mathrm{TCOC}}=952$ ) and, from May 16th onwards, on a Dimension Vista ${ }^{\circ} 1500$ (Siemens Healthcare, Erlangen, Germany) $\left(\mathrm{N}_{\text {population-based }}=1442, \mathrm{~N}_{\mathrm{TCOC}}=469\right)$ using enzymatic colorimetric method.

Detection limits on the Cobas 6000 were $0.1 \mathrm{mmol} / \mathrm{L}$ for TG and TC, and $0.08 \mathrm{mmol} / \mathrm{L}$ for HDL, and on the Dimension Vista ${ }^{\circ} 1500,0.02 \mathrm{mmol} / \mathrm{L}$ for TG, $1.29 \mathrm{mmol} /$ $\mathrm{L}$ for $\mathrm{TC}$, and $0.05 \mathrm{mmol} / \mathrm{L}$ for $\mathrm{HDL}$ according to the manufacturer. Internal quality control provided intraassay coefficients of variations with the following fractions of $0.010-0.026$ for TC, $0.008-0.034$ for HDL, and $0.009-0.024$ for TG on the Cobas ${ }^{\circ} 6000$, and of $0.014-0.028$ for TC, $0.027-0.043$ for HDL, and $0.010-0.020$ for TG on the Dimension Vista 1500 .

To ensure comparability of TC, HDL, and TG concentrations measured on the Cobas ${ }^{\circ} 6000$ and Dimension Vista 1500 , routine laboratory data from 2012 and 2014 were extracted from the laboratory information system in order to compare the two analyzers. Only data from adults (age 18 - 99 years) were included (Cobas, 2012: $N=37,222 / 34,744 / 31,615$ and Dimension Vista, 2014: $N=33,126 / 34,436 / 36,980$ for $\mathrm{TC} / \mathrm{HDL} / \mathrm{TG}$, respectively). Extreme values, defined as over/under the mean $+/-1.5$ inter-quartile range, were excluded (Cobas, 2012: $N=1404 / 1749 / 2343$ and Dimension Vista, 2014: $N=1262 / 1801 / 2600$ ) (Additional file 1: Table S1). The mean of TC concentrations was $0.26 \mathrm{mmol} / \mathrm{L}$ and of HDL $0.06 \mathrm{mmol} / \mathrm{L}$ lower when measured on the Dimension Vista ${ }^{\circ} 1500$ compared to the Cobas ${ }^{\circ} 6000$. The mean of triglyceride concentrations was $0.08 \mathrm{mmol} / \mathrm{L}$ higher on the Dimension Vista ${ }^{\circ} 1500$ compared to the Cobas ${ }^{\circ}$ 6000 , with a tendency to a slight increase in the difference in higher concentrations (Additional files 2, 3 and 4: Figures S1-S3). To account for these differences in measurement methods, in the present study, TC and HDL concentrations measured with the Cobas 6000 were deducted by 0.26 and $0.06 \mathrm{mmol} / \mathrm{L}$, respectively. TG concentrations measured on Cobas $^{\circ} 6000$ were multiplied by 1.17 and deducted by $0.16 \mathrm{mmol} / \mathrm{L}$. The Friedewald Formula was used to calculate the LDL concentration [27]. Non-HDL was calculated as TC - HDL.

\section{Dyslipidemia}

Dyslipidemia was defined according to the American Heart Associations classification corresponding to the 95th percentile in a American population as total cholesterol $>5.2 \mathrm{mmol} / \mathrm{L}(200 \mathrm{mg} / \mathrm{dl}), \mathrm{LDL}>3.4 \mathrm{mmol} / \mathrm{L}(130 \mathrm{mg} / \mathrm{dl})$, $\mathrm{HDL}<0.9 \mathrm{mmol} / \mathrm{L}(35 \mathrm{mg} / \mathrm{dl})$, or triglycerides $>1.7 \mathrm{mmol} /$ $\mathrm{L}(150 \mathrm{mg} / \mathrm{dl})$, or a combination thereof [3].

\section{Statistical methods}

All statistical calculations were performed using the statistical software $\mathrm{R}$ (version 3.2.4) [28]. The Wilcoxon signed rank test was used to determine differences between sexes in the descriptive statistics. Thereafter, all analyses were performed stratified by sex. Percentiles 
and smoothed percentile curves were generated using the Generalized Additive Models for Location Scale and Shape (gamlss) package [29] with the penalized cubic spline function and the Box-Cox $t$-distribution family or the Box-Cox Power Exponential distribution family (best fit determined by the Akaike Information Criterion). The models were tested using qq-plots and worm-plots. The effects of puberty were investigated for each sex using generalized linear models adjusted for BMI SDS. In the linear regressions, concentrations of TG were logarithmically transformed to achieve a normal distribution of residuals. Effects of age within each sex were investigated using analysis of variance and Tukey Honest Significant Difference method on normally distributed data, and with the Kruskal-Wallis test and Pairwise Wilcoxon test on non-normally distributed data, with participants grouped in tertiles according to ages in the population-based cohort: young (corresponding to age $<10.1$ years in girls. And to age $<9.3$ years in boys), middle (corresponding to age $>=10.1$ and $<13.8$ years in girls. And to age $>=9.3$ and $<12.7$ years in boys), and old (corresponding to age $>=13.8$ years in girls. And to age $>12.7$ years in boys). Normality of data was evaluated using histograms and qq-plots. Differences between mean fasting lipid concentrations between cohorts within age groups for each sex were investigated using Student's t-test on normally distributed data, and Wilcoxon rank sum test on non-normally distributed data. Odds ratios (OR) were calculated using logistic regression adjusted for age, sex, and pubertal developmental stage.

\section{Results}

From the population-based cohort, 2141 (1275 girls) children and adolescents with a median age of 11.5 years were included in the study. Of these, $17.3 \%(N=371)$ were overweight/obese (BMI > 90th percentile) and 6.0\% $(N=128)$ were underweight (BMI $<10$ th percentile) [22]. As there were significant differences between sexes in age, and in concentrations of TC, LDL, non-HDL, and triglycerides $(p<0.05)$, all analyses were performed stratified by sex. Descriptive data on the population-based cohort and the TCOC cohort are presented in Table 1 and percentiles for fasting plasma concentrations of TC, LDL, HDL, nonHDL, and TG in the population-based cohort in Table 2.

The percentile curves along with the data-points from the population-based cohort are provided in Figs. 2, 3, 4, 5 and 6 . In addition, percentile curves for the TCOC cohort are shown in the corresponding graphs (Figs. 2, 3, 4, 5 and 6). The same percentiles for the normal weight subgroup of the population-based cohort are presented in Additional file 5: Table S2. The corresponding centiles in the total population for the most part differed from the normal weight subgroup on the second decimal of the lipid concentrations; there was a tendency for a difference on the first decimal of 0.1 in the upper centiles.
Table 1 Descriptive information on the population-based cohort, and The Children's Obesity Clinic (TCOC) cohort with overweight/ obesity

\begin{tabular}{|c|c|c|c|c|}
\hline & \multicolumn{2}{|c|}{ Population-based } & \multicolumn{2}{|l|}{ TCOC } \\
\hline & Girls & Boys & Girls & Boys \\
\hline N & 1275 & 866 & 774 & 647 \\
\hline Age, years & $\begin{array}{l}11.9 \\
(6.0-19.0)\end{array}$ & $\begin{array}{l}11.0^{*} \\
(6.1-18.9)\end{array}$ & $\begin{array}{l}11.7 \\
(2.0-24.7)\end{array}$ & $\begin{array}{l}11.8^{*} \\
(2.8-21.4)\end{array}$ \\
\hline BMI SDS & $\begin{array}{l}0.25^{* *} \\
(-3.07-3.71)\end{array}$ & $\begin{array}{l}0.26^{* *} \\
(-3.48-4.54)\end{array}$ & $\begin{array}{l}2.7^{* *} \\
(1.4-6.2)\end{array}$ & $\begin{array}{l}3.1^{* *} \\
(1.38-6.1)\end{array}$ \\
\hline TC mmol/L & $\begin{array}{l}3.9^{*} \\
(2.0-7.5)\end{array}$ & $\begin{array}{l}3.7^{* *} \\
(1.9-6.0)\end{array}$ & $\begin{array}{l}3.9^{*} \\
(1.7-6.9)\end{array}$ & $\begin{array}{l}4.0^{* *} \\
(1.7-7.2)\end{array}$ \\
\hline LDL mmol/L & $\begin{array}{l}2.0^{* *} \\
(0.3-5.7)\end{array}$ & $\begin{array}{l}1.9^{* *} \\
(0.6-4.1)\end{array}$ & $\begin{array}{l}2.3^{* *} \\
(0.5-5.8)\end{array}$ & $\begin{array}{l}2.3^{* *} \\
(0.2-5.2)\end{array}$ \\
\hline $\mathrm{HDL} \mathrm{mmol} / \mathrm{L}$ & $\begin{array}{l}1.5^{* *} \\
(0.6-2.8)\end{array}$ & $\begin{array}{l}1.5^{* *} \\
(0.5-2.7)\end{array}$ & $\begin{array}{l}1.1^{* *} \\
(0.5-2.3)\end{array}$ & $\begin{array}{l}1.1^{* *} \\
(0.4-2.3)\end{array}$ \\
\hline $\begin{array}{l}\text { Non-HDL } \\
\mathrm{mmol} / \mathrm{L}\end{array}$ & $\begin{array}{l}2.4^{* *} \\
(0.4-6.1)\end{array}$ & $\begin{array}{l}2.3^{* *} \\
(0.8-4.8)\end{array}$ & $\begin{array}{l}2.8^{* *} \\
(1.0-6.4)\end{array}$ & $\begin{array}{l}2.8^{* *} \\
(0.6-6.0)\end{array}$ \\
\hline TG mmol/L & $\begin{array}{l}0.7^{* *} \\
(0.1-2.8)\end{array}$ & $\begin{array}{l}0.5^{* *} \\
(0.1-2.9)\end{array}$ & $\begin{array}{l}0.9^{* *} \\
(0.1-4.9)\end{array}$ & $\begin{array}{l}0.9^{* *} \\
(0.1-4.6)\end{array}$ \\
\hline
\end{tabular}

Data are medians and ranges. Lipids are fasting plasma concentrations of total cholesterol $(T C)$, low-density lipoprotein cholesterol $(L D L)$, high-density lipoprotein cholesterol (HDL), non-HDL, and triglycerides (TG). Significant $P$-values reflect differences between the population-based cohort and the TCOC cohort for each sex. ${ }^{*} P<0.05 .{ }^{*} P<0.0001$

\section{Fasting plasma total cholesterol}

In girls, the TC concentrations (Fig. 2a) were $0.1 \mathrm{mmol} /$ $\mathrm{L}$ higher in the youngest tertile compared to the middle tertile (95\% confidence interval (CI): [0.01 - 0.22], $P=0.03$ ) and $0.2 \mathrm{mmol} / \mathrm{L}$ higher compared to the oldest tertile ( $95 \% \mathrm{CI}$ : $\left.[0.23-0.33], P=2.3^{*} 10^{-6}\right)$. Mean concentrations in girls in the TCOC cohort differed from the population-based cohort with higher values only in the oldest age group $(P=0.0018)$. In boys, the TC concentration (Fig. 2b) was $0.4 \mathrm{mmol} / \mathrm{L}$ lower in the oldest tertile compared to the youngest tertile $(95 \% \mathrm{CI}$ : [0.23 - 0.48], $P<0.00001$ ) and $0.5 \mathrm{mmol} / \mathrm{L}$ lower compared to the middle tertile (95\% CI: [0.34 - 0.59], $P<0.00001)$. The levels of TC in boys from the TCOC cohort were stable and higher than in boys in the population-based cohort in the middle and oldest age groups $(P<0.03)$.

\section{Fasting plasma LDL}

In girls, the LDL concentrations (Fig. 3a) were $0.1 \mathrm{mmol} /$ $\mathrm{L}$ higher in the youngest population-based tertile compared to the middle tertile (95\% CI: [0.04 - 0.24], $P=0.0032)$ and $0.2 \mathrm{mmol} / \mathrm{L}$ higher compared to the oldest tertile (95\% CI: $\left.[0.11-0.30], P=2.7^{* 1} 10^{-6}\right)$, but remained stable at a higher level throughout all ages in the TCOC cohort $(P<0.002)$. The concentrations of LDL (Fig. 3b) in boys were $0.2 \mathrm{mmol} / \mathrm{L}$ higher in the youngest tertile compared to the oldest tertile $(95 \% \mathrm{CI}$ : $[0.10-0.32$, $P=1.8^{*} 10^{-5}$ ), and $0.3 \mathrm{mmol} / \mathrm{L}$ higher (95\% CI:[0.15;0.37], 
Table 2 Percentiles for fasting plasma concentrations of TC, LDL, HDL, non-HDL, and TG in the population-based cohort

\begin{tabular}{|c|c|c|c|c|c|c|c|c|c|c|c|c|c|c|c|c|c|c|c|c|c|c|c|c|c|c|c|c|c|}
\hline \multirow{2}{*}{\multicolumn{2}{|c|}{$\begin{array}{l}\text { Age } \\
\text { (years) }\end{array}$}} & \multicolumn{14}{|c|}{ Girls } & \multicolumn{14}{|c|}{ Boys } \\
\hline & & 6 & 7 & 8 & 9 & 10 & 11 & 12 & 13 & 14 & 15 & 16 & 17 & 18 & 19 & 6 & 7 & 8 & 9 & 10 & 11 & 12 & 13 & 14 & 15 & 16 & 17 & 18 & 19 \\
\hline \multirow{7}{*}{$\begin{array}{c}\mathrm{TC} \\
(\mathrm{mmol} / \mathrm{L})\end{array}$} & 5 th & 2.9 & 2.9 & 2.9 & 2.9 & 2.8 & 2.8 & 2.8 & 2.7 & 2.7 & 2.7 & 2.7 & 2.7 & 2.7 & 2.8 & 2.6 & 2.7 & 2.7 & 2.7 & 2.8 & 2.8 & 2.7 & 2.6 & 2.5 & 2.4 & 2.4 & 2.4 & 2.4 & 2.5 \\
\hline & 5th & 3.1 & 3.1 & 3.0 & 3.0 & 3.0 & 3.0 & 2.9 & 2.9 & 2.8 & 2.8 & 2.9 & 2.9 & 2.9 & 2.9 & 2.8 & 2.8 & 2.9 & 2.9 & 2.9 & 2.9 & 2.9 & 2.8 & 2.6 & 2.6 & 2.5 & 2.5 & 2.6 & 2.6 \\
\hline & 10th & 3.3 & 3.3 & 3.2 & 3.2 & 3.2 & 3.2 & 3.1 & 3.1 & 3.0 & 3.0 & 3.0 & 3.1 & 3.1 & 3.1 & 3.0 & 3.0 & 3.1 & 3.1 & 3.1 & 3.1 & 3.1 & 3.0 & 2.8 & 2.8 & 2.7 & 2.7 & 2.7 & 2.8 \\
\hline & 50th & 4.0 & 4.0 & 4.0 & 4.0 & 4.0 & 3.9 & 3.9 & 3.8 & 3.8 & 3.7 & 3.8 & 3.8 & 3.8 & 3.9 & 3.7 & 3.8 & 3.8 & 3.9 & 3.9 & 3.9 & 3.9 & 3.7 & 3.5 & 3.4 & 3.4 & 3.4 & 3.4 & 3.5 \\
\hline & 90th & 5.0 & 5.0 & 5.0 & 4.9 & 4.9 & 4.8 & 4.8 & 4.7 & 4.6 & 4.6 & 4.7 & 4.7 & 4.7 & 4.8 & 4.6 & 4.6 & 4.7 & 4.8 & 4.8 & 4.8 & 4.8 & 4.6 & 4.3 & 4.2 & 4.2 & 4.2 & 4.2 & 4.3 \\
\hline & 95th & 5.3 & 5.3 & 5.3 & 5.3 & 5.2 & 5.2 & 5.1 & 5.0 & 4.9 & 4.9 & 5.0 & 5.0 & 5.1 & 5.1 & 4.9 & 4.9 & 5.0 & 5.1 & 5.1 & 5.1 & 5.1 & 4.9 & 4.6 & 4.5 & 4.5 & 4.4 & 4.5 & 4.6 \\
\hline & 97.5th & 5.6 & 5.6 & 5.6 & 5.6 & 5.5 & 5.5 & 5.4 & 5.3 & 5.2 & 5.2 & 5.3 & 5.3 & 5.4 & 5.4 & 5.2 & 5.2 & 5.3 & 5.3 & 5.4 & 5.4 & 5.4 & 5.1 & 4.9 & 4.8 & 4.7 & 4.7 & 4.7 & 4.8 \\
\hline \multirow{7}{*}{$\begin{array}{c}\mathrm{LDL} \\
(\mathrm{mmol} / \mathrm{L})\end{array}$} & 2.5th & 1.2 & 1.2 & 1.2 & 1.1 & 1.1 & 1.1 & 1.1 & 1.0 & 1.0 & 1.0 & 1.0 & 1.1 & 1.1 & 1.1 & 1.0 & 1.0 & 1.0 & 1.0 & 1.0 & 1.0 & 1.0 & 1.0 & 0.9 & 0.9 & 0.9 & 0.9 & 0.9 & 1.0 \\
\hline & 5th & 1.3 & 1.3 & 1.3 & 1.3 & 1.3 & 1.2 & 1.2 & 1.2 & 1.2 & 1.2 & 1.2 & 1.2 & 1.2 & 1.2 & 1.2 & 1.2 & 1.2 & 1.2 & 1.2 & 1.2 & 1.2 & 1.1 & 1.1 & 1.1 & 1.0 & 1.0 & 1.1 & 1.1 \\
\hline & 10th & 1.5 & 1.5 & 1.5 & 1.5 & 1.5 & 1.4 & 1.4 & 1.4 & 1.3 & 1.3 & 1.4 & 1.4 & 1.4 & 1.4 & 1.3 & 1.3 & 1.4 & 1.4 & 1.4 & 1.4 & 1.3 & 1.3 & 1.2 & 1.2 & 1.2 & 1.2 & 1.2 & 1.2 \\
\hline & 50th & 2.2 & 2.2 & 2.2 & 2.2 & 2.1 & 2.1 & 2.0 & 2.0 & 1.9 & 1.9 & 2.0 & 2.0 & 2.0 & 2.1 & 2.0 & 2.0 & 2.0 & 2.0 & 2.0 & 2.0 & 2.0 & 1.9 & 1.8 & 1.8 & 1.8 & 1.8 & 1.8 & 1.8 \\
\hline & 90th & 3.1 & 3.1 & 3.1 & 3.0 & 3.0 & 2.9 & 2.8 & 2.7 & 2.7 & 2.7 & 2.7 & 2.8 & 2.8 & 2.9 & 2.7 & 2.8 & 2.8 & 2.8 & 2.8 & 2.8 & 2.8 & 2.7 & 2.6 & 2.5 & 2.5 & 2.5 & 2.5 & 2.6 \\
\hline & 95th & 3.4 & 3.4 & 3.4 & 3.3 & 3.3 & 3.2 & 3.1 & 3.0 & 3.0 & 3.0 & 3.0 & 3.1 & 3.1 & 3.2 & 3.0 & 3.0 & 3.1 & 3.1 & 3.1 & 3.1 & 3.0 & 2.9 & 2.8 & 2.7 & 2.7 & 2.7 & 2.8 & 2.8 \\
\hline & 97.5th & 3.8 & 3.7 & 3.7 & 3.7 & 3.6 & 3.5 & 3.4 & 3.3 & 3.3 & 3.3 & 3.3 & 3.4 & 3.4 & 3.5 & 3.3 & 3.3 & 3.3 & 3.4 & 3.4 & 3.4 & 3.3 & 3.2 & 3.0 & 3.0 & 3.0 & 3.0 & 3.0 & 3.1 \\
\hline \multirow{7}{*}{$\begin{array}{c}\mathrm{HDL} \\
(\mathrm{mmol} / \mathrm{L})\end{array}$} & 2.5th & 1.0 & 1.0 & 1.0 & 0.9 & 0.9 & 0.9 & 0.9 & 0.9 & 0.9 & 0.9 & 0.9 & 0.9 & 0.9 & 0.9 & 1.0 & 1.0 & 1.0 & 1.0 & 1.0 & 1.0 & 1.0 & 0.9 & 0.9 & 0.8 & 0.8 & 0.8 & 0.8 & 0.8 \\
\hline & 5th & 1.1 & 1.1 & 1.0 & 1.0 & 1.0 & 1.0 & 1.0 & 1.0 & 1.0 & 1.0 & 1.0 & 1.0 & 1.0 & 1.0 & 1.0 & 1.1 & 1.1 & 1.1 & 1.1 & 1.1 & 1.0 & 1.0 & 0.9 & 0.9 & 0.9 & 0.8 & 0.8 & 0.9 \\
\hline & 10th & 1.2 & 1.2 & 1.1 & 1.1 & 1.1 & 1.1 & 1.1 & 1.1 & 1.1 & 1.1 & 1.1 & 1.1 & 1.1 & 1.1 & 1.1 & 1.2 & 1.2 & 1.2 & 1.2 & 1.2 & 1.1 & 1.1 & 1.0 & 1.0 & 0.9 & 0.9 & 0.9 & 0.9 \\
\hline & 50th & 1.5 & 1.5 & 1.5 & 1.5 & 1.5 & 1.5 & 1.5 & 1.5 & 1.5 & 1.4 & 1.4 & 1.4 & 1.4 & 1.4 & 1.5 & 1.5 & 1.6 & 1.6 & 1.6 & 1.6 & 1.5 & 1.5 & 1.4 & 1.3 & 1.3 & 1.2 & 1.2 & 1.2 \\
\hline & 90th & 2.0 & 2.0 & 2.0 & 2.0 & 1.9 & 1.9 & 1.9 & 1.9 & 1.9 & 1.9 & 1.9 & 1.8 & 1.8 & 1.8 & 2.0 & 2.0 & 2.0 & 2.1 & 2.1 & 2.0 & 2.0 & 1.9 & 1.8 & 1.7 & 1.6 & 1.6 & 1.6 & 1.6 \\
\hline & 95th & 2.2 & 2.1 & 2.1 & 2.1 & 2.1 & 2.1 & 2.1 & 2.0 & 2.0 & 2.0 & 2.0 & 2.0 & 2.0 & 2.0 & 2.1 & 2.2 & 2.2 & 2.2 & 2.2 & 2.2 & 2.2 & 2.1 & 1.9 & 1.8 & 1.8 & 1.7 & 1.7 & 1.8 \\
\hline & 97.5th & 2.3 & 2.3 & 2.3 & 2.3 & 2.2 & 2.2 & 2.2 & 2.2 & 2.2 & 2.2 & 2.1 & 2.1 & 2.1 & 2.1 & 2.3 & 2.3 & 2.3 & 2.4 & 2.4 & 2.4 & 2.3 & 2.2 & 2.1 & 2.0 & 1.9 & 1.9 & 1.9 & 1.9 \\
\hline \multirow{7}{*}{$\begin{array}{l}\text { Non-HDL } \\
(\mathrm{mmol} / \mathrm{L})\end{array}$} & 2.5th & 1.4 & 1.4 & 1.4 & 1.4 & 1.4 & 1.4 & 1.3 & 1.3 & 1.3 & 1.3 & 1.3 & 1.4 & 1.4 & 1.4 & 1.2 & 1.3 & 1.3 & 1.3 & 1.3 & 1.3 & 1.3 & 1.3 & 1.3 & 1.2 & 1.2 & 1.2 & 1.2 & 1.3 \\
\hline & 5th & 1.6 & 1.6 & 1.6 & 1.6 & 1.6 & 1.5 & 1.5 & 1.5 & 1.5 & 1.5 & 1.5 & 1.5 & 1.6 & 1.6 & 1.4 & 1.4 & 1.4 & 1.5 & 1.5 & 1.5 & 1.5 & 1.4 & 1.4 & 1.4 & 1.4 & 1.4 & 1.4 & 1.4 \\
\hline & 10th & 1.8 & 1.8 & 1.8 & 1.8 & 1.8 & 1.7 & 1.7 & 1.7 & 1.7 & 1.7 & 1.7 & 1.7 & 1.8 & 1.8 & 1.6 & 1.6 & 1.6 & 1.6 & 1.7 & 1.7 & 1.6 & 1.6 & 1.6 & 1.6 & 1.5 & 1.5 & 1.6 & 1.6 \\
\hline & 50th & 2.5 & 2.5 & 2.5 & 2.5 & 2.5 & 2.5 & 2.4 & 2.4 & 2.4 & 2.4 & 2.4 & 2.4 & 2.5 & 2.5 & 2.2 & 2.3 & 2.3 & 2.3 & 2.4 & 2.4 & 2.3 & 2.3 & 2.2 & 2.2 & 2.2 & 2.2 & 2.2 & 2.2 \\
\hline & 90th & 3.4 & 3.4 & 3.4 & 3.4 & 3.4 & 3.3 & 3.3 & 3.2 & 3.2 & 3.2 & 3.3 & 3.3 & 3.4 & 3.4 & 3.0 & 3.1 & 3.1 & 3.2 & 3.2 & 3.2 & 3.2 & 3.1 & 3.1 & 3.0 & 3.0 & 3.0 & 3.0 & 3.0 \\
\hline & 95th & 3.8 & 3.8 & 3.8 & 3.7 & 3.7 & 3.7 & 3.6 & 3.5 & 3.5 & 3.5 & 3.6 & 3.6 & 3.7 & 3.8 & 3.3 & 3.3 & 3.4 & 3.4 & 3.5 & 3.5 & 3.5 & 3.4 & 3.3 & 3.3 & 3.3 & 3.2 & 3.3 & 3.3 \\
\hline & 97.5th & 4.1 & 4.1 & 4.1 & 4.1 & 4.0 & 4.0 & 3.9 & 3.9 & 3.8 & 3.8 & 3.9 & 4.0 & 4.0 & 4.1 & 3.5 & 3.6 & 3.6 & 3.7 & 3.7 & 3.7 & 3.7 & 3.6 & 3.6 & 3.5 & 3.5 & 3.5 & 3.5 & 3.5 \\
\hline & 2.5th & 0.2 & 0.2 & 0.3 & 0.3 & 0.3 & 0.3 & 0.3 & 0.3 & 0.3 & 0.3 & 0.3 & 0.3 & 0.3 & 0.3 & 0.2 & 0.2 & 0.2 & 0.2 & 0.2 & 0.2 & 0.3 & 0.3 & 0.3 & 0.3 & 0.3 & 0.3 & 0.3 & 0.3 \\
\hline & 5th & 0.3 & 0.3 & 0.3 & 0.3 & 0.3 & 0.3 & 0.3 & 0.3 & 0.3 & 0.4 & 0.4 & 0.4 & 0.4 & 0.4 & 0.2 & 0.2 & 0.2 & 0.3 & 0.3 & 0.3 & 0.3 & 0.3 & 0.3 & 0.3 & 0.3 & 0.3 & 0.3 & 0.4 \\
\hline & 10th & 0.3 & 0.3 & 0.3 & 0.4 & 0.4 & 0.4 & 0.4 & 0.4 & 0.4 & 0.4 & 0.4 & 0.4 & 0.4 & 0.5 & 0.3 & 0.3 & 0.3 & 0.3 & 0.3 & 0.3 & 0.3 & 0.4 & 0.4 & 0.4 & 0.4 & 0.4 & 0.4 & 0.4 \\
\hline & 50th & 0.5 & 0.6 & 0.6 & 0.6 & 0.6 & 0.6 & 0.6 & 0.7 & 0.7 & 0.7 & 0.7 & 0.7 & 0.8 & 0.8 & 0.5 & 0.5 & 0.5 & 0.5 & 0.5 & 0.5 & 0.6 & 0.6 & 0.6 & 0.6 & 0.7 & 0.7 & 0.7 & 0.7 \\
\hline & 90th & 0.9 & 1.0 & 1.0 & 1.0 & 1.0 & 1.1 & 1.1 & 1.1 & 1.2 & 1.2 & 1.2 & 1.3 & 1.3 & 1.3 & 0.8 & 0.8 & 0.8 & 0.8 & 0.9 & 0.9 & 1.0 & 1.0 & 1.1 & 1.1 & 1.1 & 1.1 & 1.2 & 1.2 \\
\hline & 95th & 1.1 & 1.1 & 1.2 & 1.2 & 1.2 & 1.3 & 1.3 & 1.3 & 1.4 & 1.4 & 1.5 & 1.5 & 1.5 & 1.6 & 0.9 & 1.0 & 1.0 & 1.0 & 1.0 & 1.1 & 1.1 & 1.2 & 1.3 & 1.3 & 1.3 & 1.4 & 1.4 & 1.4 \\
\hline & 97.5th & 1.3 & 1.3 & 1.4 & 1.4 & 1.4 & 1.5 & 1.5 & 1.6 & 1.6 & 1.7 & 1.7 & 1.7 & 1.8 & 1.8 & 1.1 & 1.1 & 1.1 & 1.2 & 1.2 & 1.3 & 1.4 & 1.4 & 1.5 & 1.5 & 1.6 & 1.6 & 1.6 & 1.7 \\
\hline
\end{tabular}

The 2.5th, 5th, 10th, 50th, 90th, 95th, and 97.5th percentile for each age group in girls and boys are presented

$P<0.000001)$ compared to the middle tertile. The LDL concentrations in boys from the TCOC cohort were higher than in boys in the population-based cohort at all ages $(P<0.0001)$.

\section{Fasting plasma HDL}

In girls, the HDL concentrations (Fig. 4a) in the population-based cohort were $0.1 \mathrm{mmol} / \mathrm{L}$ lower in the oldest tertile compared to the middle tertile (95\% CI: [0.02 - 0.12], $P=0.004$ ) and $0.1 \mathrm{mmol} / \mathrm{L}$ lower compared to the youngest tertile (95\% CI: [0.04 - 0.15], $P=4.4 * 10^{-5}$ ). In girls from the TCOC cohort, the HDL concentrations exhibited a constantly lower level $\left(P<2.2^{*} 10^{-16}\right)$ in all three age groups. The HDL concentrations (Fig. 4b) in boys in the population-based cohort in the oldest tertile were $0.2 \mathrm{mmol} / \mathrm{L}$ lower 

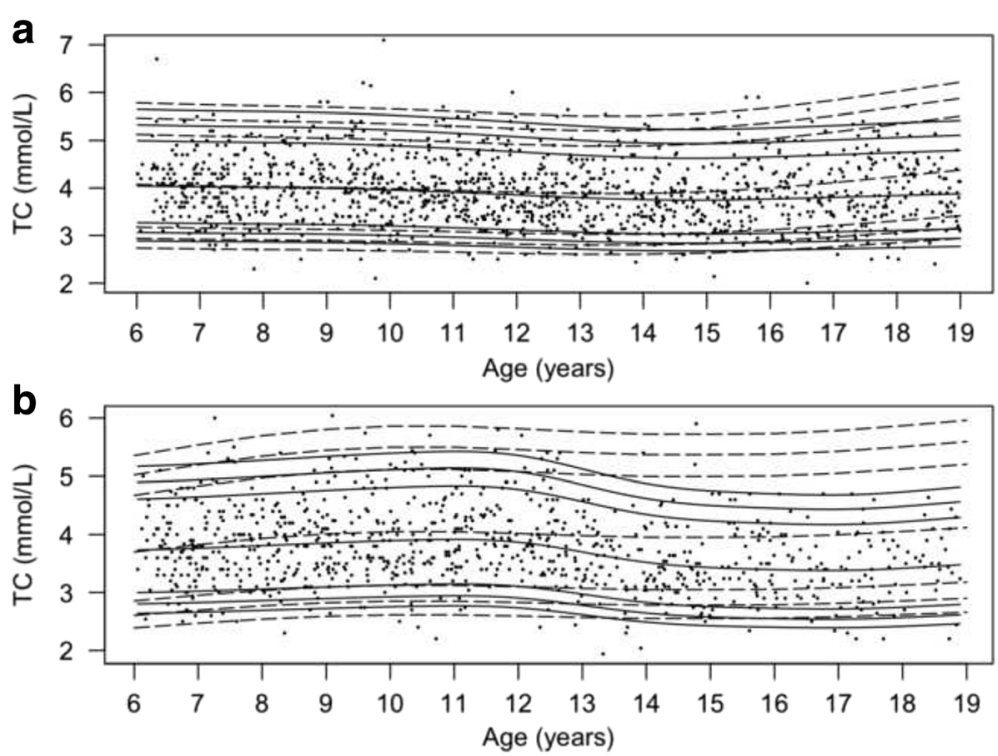

Fig. 2 Percentile curves for concentrations of fasting plasma total cholesterol. Smoothed 2.5th, 5th, 50th, 90th, 95th and 97.5th percentile curves for TC in girls (a) and boys (b). Full lines represent the total reference population, and dotted lines represent the cohort from The Children's Obesity Clinic with overweight/obesity. The dots represent the participants from the population-based cohort. Concentrations of TC are in mmol/L

compared to the youngest tertile (95\% CI: [0.16 - 0.29], $P<0.00001)$ and $0.2 \mathrm{mmol} / \mathrm{L}$ lower compared to the middle tertile (95\% CI:[0.18;0.31], $P>0.00001)$. In boys, the HDL concentrations in the TCOC cohort were lower than in the population-based cohort at all ages $\left(P<6.0^{*} 10^{-15}\right)$ and were significantly higher in the youngest age group compared to the oldest age group (95\% CI: [0.17 - 0.30], $P=3.6^{*} 10^{-12}$ ).
Fasting plasma non-HDL

In girls, the concentration of non-HDL (Fig. 5a) did not differ between the three age groups in the populationbased cohort $(P>0.05)$. In girls from the TCOC cohort, the non-HDL concentrations exhibited a constantly higher level in all three age groups compared to the population-based cohort $(P<0.0001)$. In boys, the concentration of non-HDL was $0.2 \mathrm{mmol} / \mathrm{L}$ lower in the

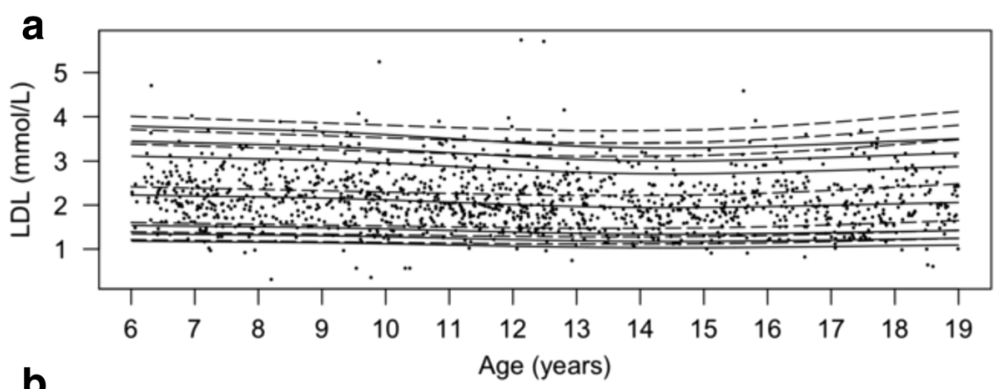

b

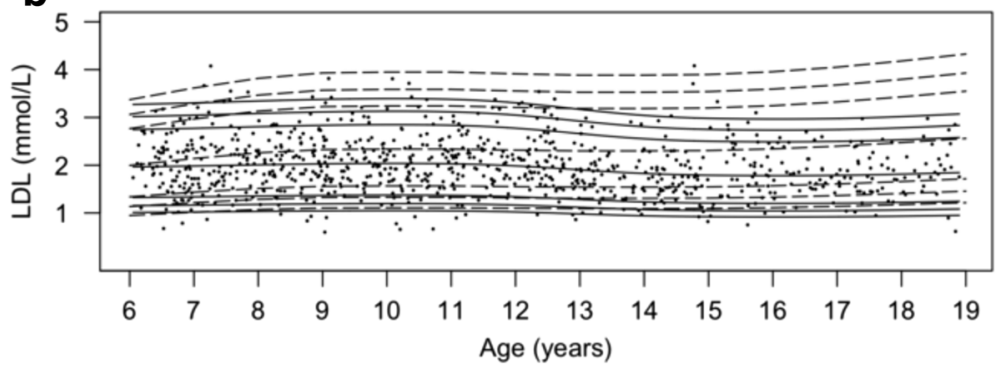

Fig. 3 Percentile curves for concentrations of fasting plasma low-density lipoprotein. Smoothed 2.5th, 5th, 50th, 90th, 95th and 97.5th percentile curves for LDL in girls (a) and boys (b). Full lines represent the total reference population, and dotted lines represent the cohort from The Children's Obesity Clinic with overweight/obesity. The dots represent the participants from the population-based cohort. Concentrations of LDL are in $\mathrm{mmol} / \mathrm{L}$ 

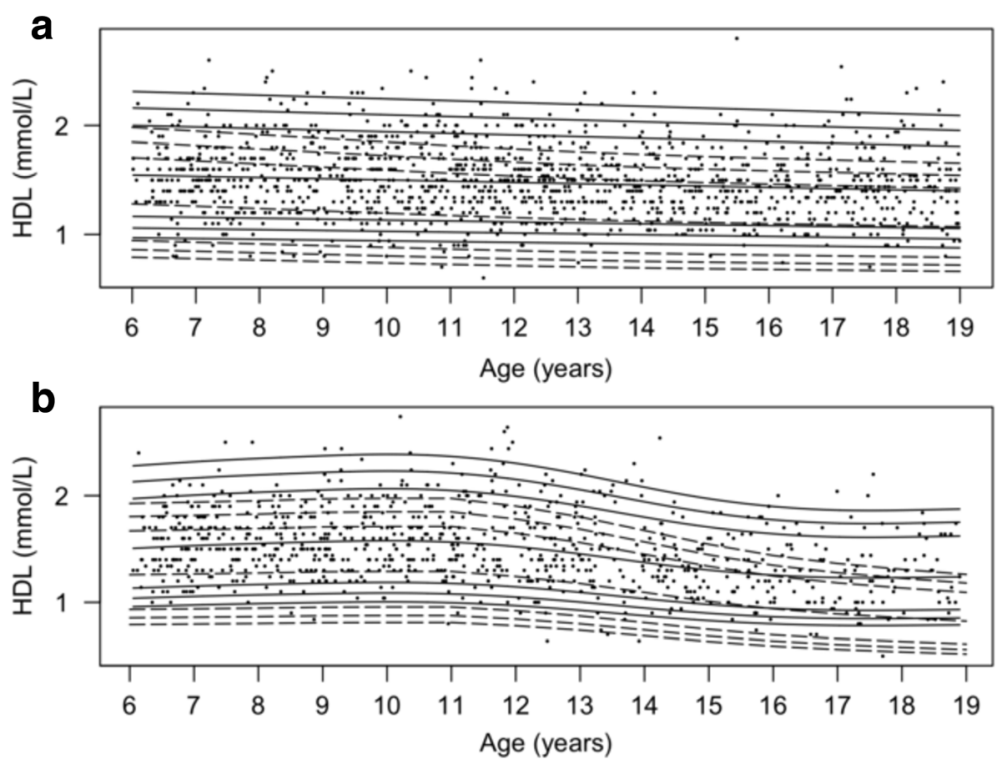

Fig. 4 Percentile curves for concentrations of fasting plasma high-density lipoprotein. Smoothed 2.5th, 5th, 50th, 90th, 95th and 97.5th percentile curves for HDL in girls (a) and boys (b). Full lines represent the total reference population, and dotted lines represent the cohort from The Children's Obesity Clinic with overweight/obesity. The dots represent the participants from the population-based cohort. Concentrations of HDL are in mmol/L

oldest tertile compared to the middle tertile (95\% CI:[0.09;0.32], $P=0.00012)$. No difference was observed between the youngest tertile and the middle or oldest tertile $(P>0.05)$. Concentrations of non-HDL in boys in the TCOC cohort were higher in all age groups $\left(P<2.4^{*} 10^{-6}\right)$.

\section{Fasting plasma triglyceride}

TG concentrations increased from the youngest to the middle tertile in girls $\left(P=2.4^{*} 10^{-5}\right)$ and boys $(P=0.00042)$, and from the middle to the oldest tertile in girls $(P=0.0011)$ and in boys $\left(P=1.8^{*} 10^{-5}\right)$ (Fig. 6a and b). TG concentrations in both girls and boys from
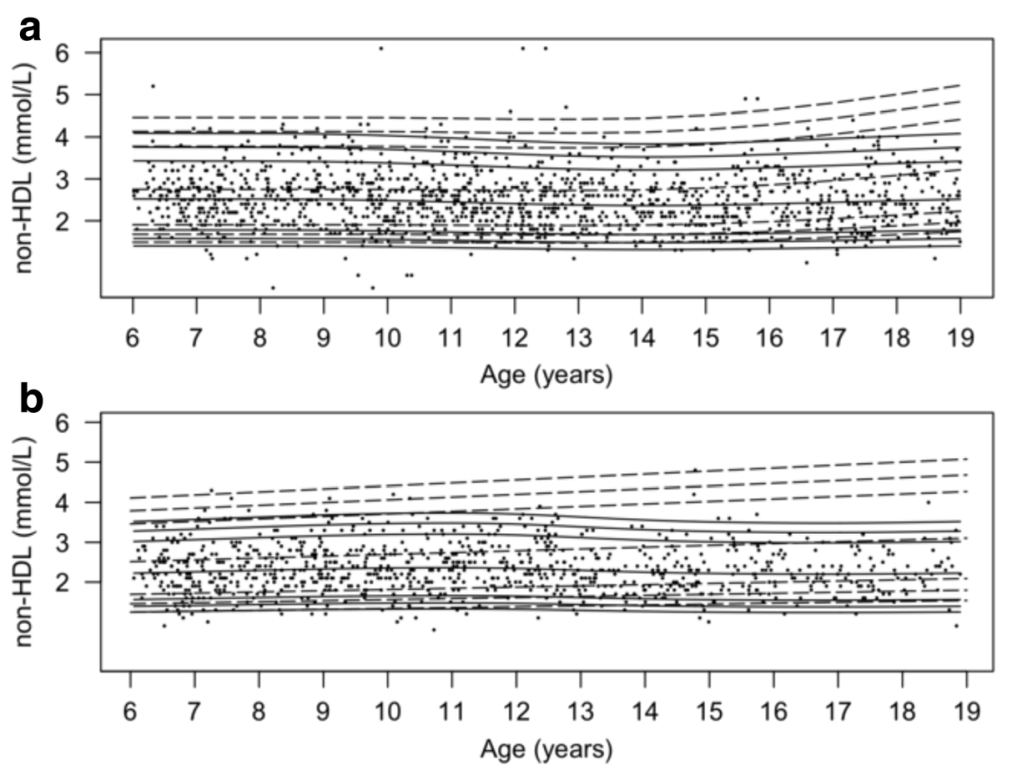

Fig. 5 Percentile curves for concentrations of fasting plasma non-high-density lipoprotein. Smoothed 2.5th, 5th, 50th, 90th, 95th and 97.5th percentile curves for non-HDL in girls (a) and boys (b). Full lines represent the total reference population, and dotted lines represent the cohort from The Children's Obesity Clinic with overweight/obesity. The dots represent the participants from the population-based cohort. Concentrations of non-HDL are in mmol/L 

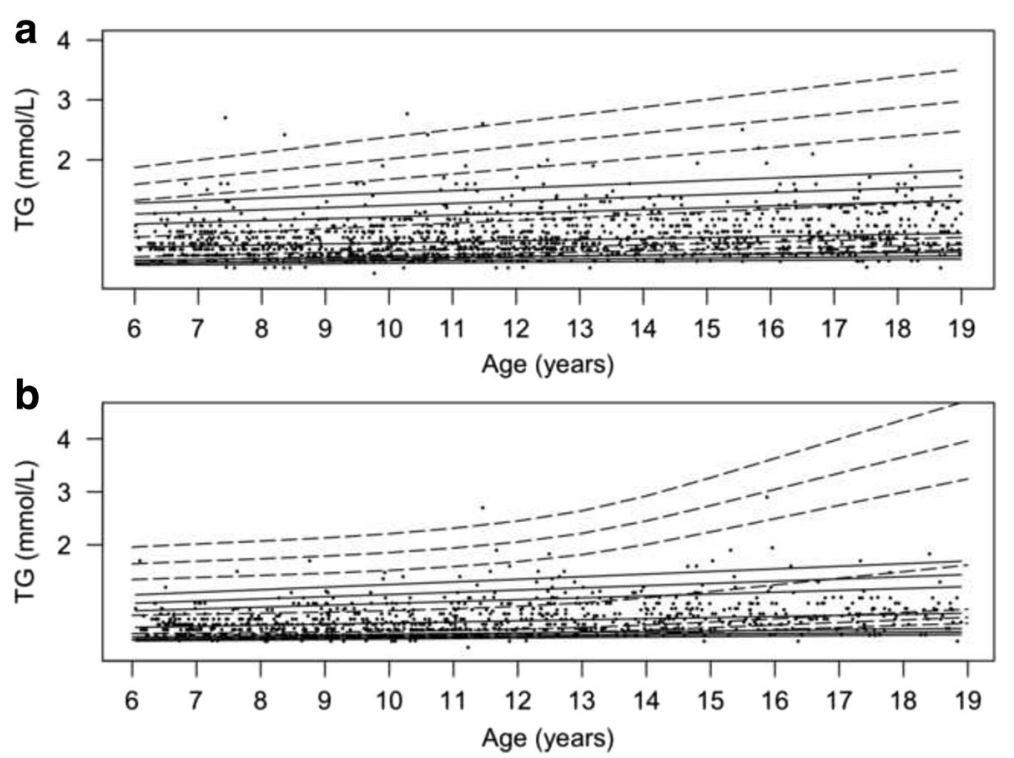

Fig. 6 Percentile curves for concentrations of fasting plasma triglycerides. Smoothed 2.5th, 5th, 50th, 90th, 95th and 97.5th percentile curves for TG in girls (a) and boys (b). Full lines represent the total reference population, and dotted lines represent the cohort from The Children's Obesity Clinic with overweight/obesity. The dots represent the participants from the population-based cohort. Concentrations of TG are in $\mathrm{mmol} / \mathrm{L}$

the TCOC cohort were higher than in the populationbased cohort at all ages $\left(P<2.2^{*} 10^{-14}\right)$. Furthermore, in girls from the TCOC cohort, concentrations of TG were higher in the oldest age group compared to the middle $\left(P=2.0^{*} 10^{-5}\right)$ and the youngest $\left(P=1.4 * 10^{-12}\right)$ age groups, and, in boys from the TCOC cohort, higher in the oldest age group compared to the middle $(P=0.035)$ and youngest age group $\left(P=1.1^{*} 10^{-9}\right)$.

\section{Puberty}

Data on pubertal developmental stages were available in $77 \%(N=984)$ of girls and in $53 \%(N=463)$ of boys in the population-based cohort. Pubertal girls exhibited a $0.2 \mathrm{mmol} / \mathrm{L}$ lower TC concentration compared to pre-pubertal girls (95\% CI:[-0.25; -0.06], $P=0.0013)$. Pubertal girls exhibited a $0.1 \mathrm{mmol} / \mathrm{L}$ lower $\mathrm{LDL}$ concentration compared to pre-pubertal girls (95\% CI:[-0.21; -0.04$], P=0.0030)$. Pubertal girls exhibited a $0.1 \mathrm{mmol} / \mathrm{L}$ lower concentration of HDL compared to pre-pubertal girls (95\% CI:[-0.11; -0.02], $P=0.0028$ ). No difference was observed in the concentrations of non-HDL in pubertal girls compared to pre-pubertal girls (95\% CI:[-0.14;0.04], $P=0.25$ ). The concentration of TG was $15 \%$ higher in pubertal girls compared to prepubertal girls (95\% CI:[1.08;1.22], $P=6.2^{*} 10^{-6}$ ).

In boys, puberty was associated with a $0.2 \mathrm{mmol} / \mathrm{L}$ lower concentration of TC (95\% CI:[-0.37; -0.11$]$, $\left.P=4.2^{*} 10^{-4}\right)$, a $0.2 \mathrm{mmol} / \mathrm{L}$ lower concentration of HDL (95\% CI:[-0.24; -0.11$], P=2.3 * 10^{-7}$ ), and a $12 \%$ higher TG concentration (95\% CI:[1.03;1.22], $P=0.0078)$ compared to pre-puberty. No differences were observed in the concentrations of LDL $(95 \%$ CI:[-0.21;0.01], $P=0.071)$ or non-HDL (95\% CI:[-0.17;0.06], $P=0.34$ ) between pubertal and pre-pubertal boys. Adjusting for age in the generalized linear models rendered all associations between lipid concentrations and puberty in girls and in boys insignificant.

Similar effects of puberty were observed in the TCOC cohort among girls as well as boys.

\section{Dyslipidemia}

The prevalence of dyslipidemia was $6.4 \%$ in the population-based cohort, and $28.0 \%$ in the TCOC cohort (Table 3). The odds ratio (OR) for exhibiting dyslipidemia was $6.2\left(95 \% \mathrm{CI}: 4.9-8.1, P<2^{*} 10^{-16}\right)$ in the TCOC cohort compared to the population-based cohort. In the population-based group, the OR for a child or adolescent with a BMI $>90$ th percentile to exhibit dyslipidemia was 2.8 (95\% CI: $1.8-4.4, P=4.9^{*} 10^{-6}$ ) compared to a child with a BMI <90th percentile, when

Table 3 Prevalence of dyslipidemia

\begin{tabular}{llll}
\hline & $\begin{array}{l}\text { TCOC } \\
\mathrm{N}(\%)\end{array}$ & $\begin{array}{l}\text { Population- } \\
\text { based cohort } \\
\mathrm{N}(\%)\end{array}$ & $\begin{array}{l}\text { Subgroup of normal } \\
\text { weight individuals } \\
\mathrm{N}(\%)\end{array}$ \\
\hline $\mathrm{TC}>5.2 \mathrm{mmol} / \mathrm{L}$ & $101(7.1 \%)$ & $71(3.3 \%)$ & $46(2.8 \%)$ \\
$\mathrm{LDL}>3.4 \mathrm{mmol} / \mathrm{L}$ & $97(6.8 \%)$ & $49(2.3 \%)$ & $33(2.0 \%)$ \\
$\mathrm{HDL}<0.9 \mathrm{mmol} / \mathrm{L}$ & $180(12.7 \%)$ & $35(1.6 \%)$ & $21(1.3 \%)$ \\
$\mathrm{TG}>1.7 \mathrm{mmol} / \mathrm{L}$ & $211(14.8 \%)$ & $27(1.3 \%)$ & $14(0.8 \%)$ \\
$\begin{array}{l}\text { One or more of } \\
\text { above }\end{array}$ & $398(28.0 \%)$ & $137(6.4 \%)$ & $86(5.2 \%)$ \\
\hline
\end{tabular}


adjusting for age, sex, and pubertal developmental stage. The OR for a child or adolescent from the TCOC cohort compared to a child or adolescent from the populationbased cohort with a BMI > 90th percentile to have dyslipidemia was 2.9 (95\% CI: $2.0-4.4, P=1.0^{*} 10^{-7}$ ). All ORs were driven by differences in BMI SDS, and became insignificant when further adjusting for BMI SDS in the models $(P>0.05)$.

\section{Discussion}

This study provides reference values for fasting plasma concentrations of TC, LDL, HDL, non-HDL, and TG in a population-based cohort of Danish/North-European White children and adolescents. In addition, the study evaluates the association of overweight and obesity with these variables. We calculated the percentiles in both the total population-based cohort and in a normalweight subgroup of the cohort. Excluding the individuals with overweight/obesity in the population-based cohort did not change the reference curves markedly other than on the first decimal in some of the upper percentiles. This offers no clinical relevance, since the accuracies of the analysis methods exhibit a higher variation than the differences in values between the total populationbased cohort and the normal-weight subgroup. We therefore generated reference percentiles for the entire population-based cohort.

Except for the concentrations of TG, the lipid concentrations varied more throughout childhood and adolescence in boys compared to girls, with the reference curves in boys exhibiting a biphasic pattern for TC, LDL, HDL, and non-HDL, and a steady increase for TG. The reference levels at the 50th and 90th percentile in both a French cohort $(N=1976$ (1004 girls), age 7 - 20 years $)$ and a German cohort $(N=2571$ (1226 girls), age 0 - 16 years), albeit showing comparable patterns throughout childhood, exhibited higher concentrations for TC, LDL, and TG, but similar levels of the HDL concentrations in both sexes compared to our study [21, 30]. Differences in overweight/obesity prevalences do not explain this difference, as the prevalences of overweight and obesity in Germany, France, and Denmark are comparable [18, 31, 32]. In addition, only lean subjects were included in the French study [30], and in the present study, the 50th percentile did not change, when including the underweight, overweight, and obese individuals from the population-based cohort.

Non-HDL concentrations among children and adolescents are more indicative of persistent dyslipidemia compared to TC, LDL, or HDL [5], and in a metaanalysis of 233,455 adults a more potent marker of cardiovascular risk than LDL [33]. In our study, concentrations of non-HDL were not affected by puberty in either sex, and in girls not affected by age. In boys, concentrations were lower in the oldest age group of boys compared with the middle age group of boys. In contrast, a study in Slovakian children and adolescents found a negative effect of age on non-HDL in both girls and boys [34].

Through all ages and in both sexes in the present study, children from the TCOC cohort exhibited higher concentrations of TC, LDL, non-HDL, and TG, and lower concentrations of HDL than the population-based cohort, underlining the reports from a previous study on the effects of obesity on fasting plasma lipid concentrations $[13,35]$. In the German cohort, the prevalence of dyslipidemia was similar to what is previously described in US children and adolescents $(N=1482$ (725 girls), age $8-17$ years) $[20,21]$. The prevalence of dyslipidemia in our cohort was considerably lower than described in both of these cohorts. The difference to the German cohort may in part be explained by their inclusion of a cohort with obesity from an obesity clinic, where the degree of obesity may have been higher than the overall degree of obesity in the population, even though the prevalence of obesity in their cohort resembled the overall German prevalence of obesity [21]. In the present study, a higher OR for dyslipidemia was observed in the TCOC cohort compared to the subgroup with overweight/obesity from the population-based cohort; a difference that was correlated with differences in BMI SDS. This indicates that differences in the degree of obesity may influence the prevalence of dyslipidemia in a given cohort. Similarly, the difference in prevalences of dyslipidemia between our cohort and the American cohort may be explained by the difference in the prevalences of obesity, being higher in USA and with increasing prevalence of extreme obesity [17-19]. In the present study we focused on fasting concentrations of lipids and dyslipidemia. Future studies should investigate the distribution and effect of obesity on other cardiovascular risk factors such as hypertension and insulin resistance, and the possible effects - individually and combined - of multiple risk factors present concomitantly in children and adolescents.

A limitation to our study was the lack of diet registration. Nevertheless, adherence to the fasting state was assured by interview on the morning of the blood sampling. If the participant was not fasting, another appointment for blood sampling was made.

During the study period, methods for blood sample analysis changed at the laboratory that analyzed our samples. This was due to hospital administrative decisions not related to this study. The comparability of the results was ensured, by applying a quality control analysis on all measurements performed at the laboratory in 2012 (Cobas ${ }^{\circ}$ 6000) and 2014 (Dimension Vista ${ }^{\circledR} 1500$ ). The variation between the Cobas 6000 and the Dimension 
Vista 1500 in measured concentrations of HDL and TG was less than the intra-assay variation, indicating that it may not have been necessary to apply a correction factor on these variables. Accordingly, applying the conversion factors on the lipid concentrations did not change any of the conclusions in the study.

In the population-based sample, the pubertal developmental stage was self-evaluated with picture pattern recognition due to practical considerations. Thus, this method of determining puberty might be less accurate than the same evaluation done by a trained pediatrician; however, self-evaluated puberty distinguishing between the pre-pubertal and pubertal stage has been shown to be reliable in epidemiological studies [26]. The effects of puberty on lipid concentrations did not differ from the effects of age in our cohorts. Thus, we consider age to be the most straightforward way to define references for fasting plasma lipid concentrations in Danish/NorthEuropean children and adolescents. The references defined by the present study are presented both as charts easy to use for the clinicians plotting the values of their patients and monitoring progressions, and in tables for integration into electronic laboratory systems.

The primary strength of the study was a large cohort of healthy Danish children recruited from schools, public dentists, and healthcare nurses in 11 municipalities in Denmark, with an extensive phenotype collected alongside biochemical markers. In addition, the TCOC cohort, a cohort of children and adolescents with overweight/obesity, was collected during the same period of time and provided information on the effects of obesity on the lipid concentrations, elucidating the health-related impact obesity has on human metabolism at an early age.

\section{Conclusion}

This study provides reference values for fasting plasma lipid concentrations for both sexes in the age range 6 - 19 years in Danish/North-European whites. Different patterns for girls and boys were observed for lipid concentrations throughout childhood and adolescence. Furthermore, the study evaluates the effects of obesity on lipid concentrations in childhood including an increased risk of dyslipidemia, which might predispose the children with obesity to premature CVD morbidity and mortality later in life.

\section{Additional files}

Additional file 1: Table S1. Summary of routine laboratory data on fasting plasma concentrations of TC, HDL, and TG from 2012 and 2014. (XLSX $8 \mathrm{~kb}$ )

Additional file 2: Figure S1. Cumulative relative frequency plots of concentrations of TC. Concentrations measured in 2012 measured on the
Cobas $^{\oplus} 6000$ (Blue curve) and in 2014 on the Dimension Vista ${ }^{\circledR} 1500$ (Red curve). (PDF $29 \mathrm{~kb}$ )

Additional file 3: Figure S2. Cumulative relative frequency plots of concentrations of HDL. Concentrations measured in 2012 measured on the Cobas $^{\circledR} 6000$ (Blue curve) and in 2014 on the Dimension Vista ${ }^{\oplus} 1500$ (Red curve). (PDF $28 \mathrm{~kb}$ )

Additional file 4: Figure S3. Cumulative relative frequency plots of concentrations of TG. Concentrations measured in 2012 measured on the Cobas $^{\oplus} 6000$ (Blue curve) and in 2014 on the Dimension Vista ${ }^{\circledR} 1500$ (Red curve). (PDF $31 \mathrm{~kb}$ )

Additional file 5: Table S2. The 2.5th, 5th, 10th, 50th, 90th, 95th, and 97.5th percentiles for lipid concentrations in girls $(N=971)$ and boys $(N=668)$ with 10 th $\leq$ BMI SDS $\leq 90$ th at ages $6-19$ years. (XLSX $44 \mathrm{~kb})$

Additional file 6: Table S3. Routine laboratory data on fasting plasma concentrations of TC, HDL, and TG from 2012. Age in years. Concentrations in $\mathrm{mmol} / \mathrm{L}$. (CSV $4181 \mathrm{~kb})$

Additional file 7: Table S4. Routine laboratory data on fasting plasma concentrations of TC, HDL, and TG from 2012. Age in years. Concentrations in $\mathrm{mmol} / \mathrm{L}$. (CSV $4279 \mathrm{~kb}$ )

Additional file 8: Table S5. Dataset from the population-based and the TCOC cohort. Age in years. Concentrations in $\mathrm{mmol} / \mathrm{L}$. Affiliation 1 and 5 : children in the TCOC cohort. Affiliation 3: children in the population-based cohort. Interval: days between blood sampling and anthropometrics. Tanner_girl: Pubertal stage 1-5 according to the Tanner classification. Tanner_boy: Pubertal stage 1-5 according to Tanner classification. (CSV 179 kb)

\section{Abbreviations}

BMI SDS: Body mass index standard deviation score; CVD: Cardiovascular disease; HDL: High-density lipoprotein; LDL: Low-density lipoprotein; TC: Total cholesterol; TG: Triglycerides

\section{Acknowledgements}

This study is part of the research activities in TARGET (The Impact of our Genomes on Individual Treatment Response in Obese Children, http://www. target.ku.dk), and BIOCHILD (Genetics and Systems Biology of Childhood Obesity in India and Denmark, http://www.biochild.ku.dk). The study is part of The Danish Childhood Obesity Biobank; ClinicalTrials.gov ID-no.: NCT00928473. The Novo Nordisk Foundation Center for Basic Metabolic Research is an independent Research Center at the University of Copenhagen partially funded by an unrestricted donation from the Novo Nordisk Foundation (http://www.meta bol.ku.dk). The authors wish to thank Mrs. Oda Troest and Mrs. Birgitte Holløse for their invaluable assistance with blood samples and database.

\section{Funding}

The Region Zealand Health Sciences Research Foundation, the Innovation Fund Denmark (grants 0603-00484B and 0603-00457B), and the Novo Nordisk Foundation (grant number NNF15OC0016544) supported this study.

\section{Availability of data and materials}

The dataset supporting the conclusions of this article are included within the article and its (Additional files 6,7 and 8: Table S3-S5). Any publications arising from the use of this dataset acknowledges the source of the dataset, its funding and the collaborative group that collected the data.

\section{Authors' contributions}

TRHN designed and conducted the research, reviewed the literature, conducted the statistical analyses, interpreted the data, and drafted the initial manuscript. $\mathrm{JCH}, \mathrm{TH}$ and OP designed the study, carried out the research, interpreted the data, and critically revised the paper. PB and LP conducted the quality control analyses of method changes, interpreted these data, and assisted in the influence of the method change. CB, CEF and ULT carried out the research, interpreted the data, and critically revised the paper. All authors approved of the final manuscript.

\section{Competing interests}

The authors declare that they have no competing interests.

Consent for publication

Not applicable. 


\section{Ethics approval and consent to participate}

All participants gave informed assent. Written informed consent was obtained from parents of participants aged younger than 18 years, and from the participants themselves if aged 18 years and older. The study is approved by the Ethics Committee of Region Zealand, Denmark (protocol no. SJ-104), and the Danish Data Protection Agency.

\section{Publisher's Note}

Springer Nature remains neutral with regard to jurisdictional claims in published maps and institutional affiliations.

\section{Author details}

'The Children's Obesity Clinic, Department of Pediatrics, Copenhagen University Hospital Holbæk, Smedelundsgade 60, DK 4300 Holbæk, Denmark. ${ }^{2}$ Novo Nordisk Foundation Center for Basic Metabolic Research, Section of Metabolic Genetics, University of Copenhagen, DK 2100 Copenhagen, Denmark ${ }^{3}$ Department of Clinical Medicine, University of Copenhagen, Copenhagen, Denmark. ${ }^{4}$ Hans Christian Andersen Children's Hospital, Odense University Hospital, Odense, Denmark. ${ }^{5}$ Department of Clinical Biochemistry, Copenhagen University Hospital Holbæk, DK 4300 Holbæk, Denmark.

\section{Received: 29 September 2016 Accepted: 22 April 2017}

Published online: 28 April 2017

\section{References}

1. Lozano R, Naghavi M, Foreman K, Lim S, Shibuya K, Aboyans V, et al. Global and regional mortality from 235 causes of death for 20 age groups in 1990 and 2010: a systematic analysis for the Global Burden of Disease Study 2010. Lancet. 2013;380(9859):2095-128.

2. Perk J, De Backer G, Gohlke H, Graham I, Reiner Z, Verschuren M, et al. European Guidelines on cardiovascular disease prevention in clinical practice (version 2012). The Fifth Joint Task Force of the European Society of Cardiology and Other Societies on Cardiovascular Disease Prevention in Clinical Practice (constituted by representatives of nine societies and by invited experts). Eur Heart J. 2012;33(13):1635-701.

3. Kavey R-EW, Daniels SR, Lauer RM, Atkins DL, Hayman LL, Taubert K. American Heart Association guidelines for primary prevention of atherosclerotic cardiovascular disease beginning in childhood. Circulation. 2003;107(11):1562-6.

4. Nomikos T, Panagiotakos D, Georgousopoulou E, Metaxa V, Chrysohoou C, Skoumas I, et al. Hierarchical modelling of blood lipids' profile and 10-year (2002-2012) all cause mortality and incidence of cardiovascular disease: the ATTICA study. Lipids Health Dis. 2015;14:108

5. Expert Panel on Integrated Guidelines for Cardiovascular Health and Risk Reduction in Children And Adolescents. Expert Panel on Integrated Guidelines for Cardiovascular Health and Risk Reduction in Children and Adolescents: Summary Report. Pediatrics. 2011;128(Supplement 5):S213-56.

6. Berenson GS, Srinivasan SR, Bao W, Newman WP, Tracy RE, Wattigney WA. Association between Multiple Cardiovascular Risk Factors and Atherosclerosis in Children and Young Adults. N Engl J Med. 1998;338(23):1650-6.

7. Juhola J, Magnussen CG, Viikari JSA, Kähönen M, Hutri-Kähönen N, Jula A, et al. Tracking of serum lipid levels, blood pressure, and body mass index from childhood to adulthood: the Cardiovascular Risk in Young Finns Study. J Pediatr. 2011;159(4):584-90

8. Camhi SM, Katzmarzyk PT. Tracking of cardiometabolic risk factor clustering from childhood to adulthood. Int J Pediatr Obes. 2010;5(2):122-9.

9. Lauer RM, Lee J, Clarke WR. Factors affecting the relationship between childhood and adult cholesterol levels: the Muscatine Study. Pediatrics. 1988;82(3):309-18

10. Bayer $\mathrm{O}$, Krüger $H$, von Kries $R$, Toschke AM. Factors associated with tracking of BMI: a meta-regression analysis on BMI tracking. Obesity (Silver Spring). 2011;19(5):1069-76.

11. Joshi SM, Katre PA, Kumaran K, Joglekar C, Osmond C, Bhat DS, et al. Tracking of cardiovascular risk factors from childhood to young adulthood the Pune Children's Study. Int J Cardiol. 2014;175(1):176-8.

12. I'Allemand D, Wiegand S, Reinehr T, Müller J, Wabitsch M, Widhalm K, et al. Cardiovascular risk in 26,008 European overweight children as established by a multicenter database. Obesity (Silver Spring). 2008;16(7):1672-9.

13. Nielsen TRH, Gamborg M, Fonvig CE, Kloppenborg J, Hvidt KN, Ibsen H, et al. Changes in lipidemia during chronic care treatment of childhood obesity. Child Obes. 2012;8(6):533-41.
14. Centers for Disease Control and Prevention (CDC). Prevalence of abnormal lipid levels among youths — United States, 1999-2006. MMWR Morb Mortal Wkly Rep. 2010;59(2):29-33.

15. Daniels SR, Greer FR. and the Committee on Nutrition. Lipid Screening and Cardiovascular Health in Childhood. Pediatrics. 2008;122(1):198-208.

16. Pearson S, Hansen B, Sørensen TIA, Baker JL. Overweight and obesity trends in Copenhagen schoolchildren from 2002 to 2007. Acta Paediatr. 2010; 99(11):1675-8.

17. Skinner AC, Perrin EM, Skelton JA. Prevalence of obesity and severe obesity in US children, 1999-2014. Obesity. 2016;24(5):1116-23.

18. Schmidt Morgen C, Rokholm B, Sjöberg Brixval C, Schou Andersen C, Geisler Andersen L, Rasmussen M, et al. Trends in prevalence of overweight and obesity in danish infants, children and adolescents-are we still on a plateau? PLoS One. 2013;8(7):e69860.

19. Ogden $\mathrm{CL}$, Carroll MD, Lawman HG, Fryar CD, Kruszon-Moran D, Kit BK, et al. Trends in Obesity Prevalence Among Children and Adolescents in the United States, 1988-1994 Through 2013-2014. JAMA. 2016;315(21):2292.

20. Kit BK, Kuklina E, Carroll MD, Ostchega Y, Freedman DS, Ogden CL. PRevalence of and trends in dyslipidemia and blood pressure among us children and adolescents, 1999-2012. JAMA Pediatr. 2015;169(3):272-9.

21. Dathan-Stumpf A, Vogel M, Hiemisch A, Thiery J, Burkhardt R, Kratzsch J, et al. Pediatric reference data of serum lipids and prevalence of dyslipidemia: Results from a population-based cohort in Germany. Clin Biochem. 2016;49:740-9.

22. Nysom K, Mølgaard C, Hutchings B, Michaelsen KF. Body mass index of 0 to 45-y-old Danes: reference values and comparison with published European reference values. Int J Obes Relat Metab Disord. 2001:25(2):177-84.

23. Cole TJ. The LMS method for constructing normalized growth standards. Eur J Clin Nutr. 1990;44(1):45-60.

24. Marshall WA, Tanner JM. Variations in pattern of pubertal changes in girls. Arch Dis Child. 1969:44(235):291-303.

25. Marshall WA, Tanner JM. Variations in the pattern of pubertal changes in boys. Arch Dis Child. 1970;45(239):13-23.

26. Rasmussen AR, Wohlfahrt-Veje C, Tefre de Renzy-Martin K, Hagen CP, Tinggaard J, Mouritsen A, et al. Validity of Self-Assessment of Pubertal Maturation. Pediatrics. 2015:135(1):86-93.

27. Johnson R, McNutt P, MacMahon S, Robson R. Use of the Friedewald formula to estimate LDL-cholesterol in patients with chronic renal failure on dialysis. Clin Chem. 1997:43(11):2183-4.

28. R Core Team. R: A Language and Environment for Statistical Computing [Internet]. Vienna: R Foundation for Statistical Computing; 2016. Available from: https://www.R-project.org.

29. Rigby RA, Stasinopoulos DM. Generalized additive models for location, scale and shape. Appl Stat. 2005:54:507-54

30. Mellerio H, Alberti C, Druet C, Capelier F, Mercat I, Josserand E, et al. Novel Modeling of Reference Values of Cardiovascular Risk Factors in Children Aged 7 to 20 Years. Pediatrics. 2012;129(4):e1020-9.

31. Olds T, Maher C, Zumin S, Péneau S, Lioret S, Castetbon K, et al. Evidence that the prevalence of childhood overweight is plateauing: data from nine countries. Int J Pediatr Obes. 2011;6(5-6):342-60.

32. Kurth B-M, Schaffrath Rosario A. Die Verbreitung von Übergewicht und Adipositas bei Kindern und Jugendlichen in Deutschland: Ergebnisse des bundesweiten Kinder- und Jugendgesundheitssurveys (KiGGS). Bundesgesundheitsbl Gesundheitsforsch Gesundheitsschutz. 2007;50(5-6):736-43.

33. Sniderman AD, Williams K, Contois JH, Monroe HM, McQueen MJ, de Graaf J, et al. A Meta-Analysis of Low-Density Lipoprotein Cholesterol, Non-HighDensity Lipoprotein Cholesterol, and Apolipoprotein B as Markers of Cardiovascular Risk. Circ Cardiovasc Qual Outcomes. 2011:4(3):337-45.

34. Alberty R, Albertyová D, Ahlers I. Distribution and correlations of non-highdensity lipoprotein cholesterol in Roma and Caucasian children: the Slovak Lipid Community Study. Coll Antropol. 2009;33(4):1015-22.

35. Friedemann C, Heneghan C, Mahtani K, Thompson M, Perera R, Ward AM. Cardiovascular disease risk in healthy children and its association with body mass index: systematic review and meta-analysis. BMJ [Internet]. 2012;345. Available from: http://www.ncbi.nlm.nih.gov/pmc/articles/PMC3458230/. Cited 15 Aug 2016. 